\title{
Микрокриогенная система Стирлинга с комбинированным регенератором и магнитокалорической ступенью охлаждения
}

\author{
А. В. Самвелов, С. Г. Ясевㄱ, А. С. Москаленкоㄱ, В. В. Старцевㄱ, О. В. Пахомов² \\ 1 Акционерное общество "Оптико-механическое конструкторское бюро "АСТРОН", \\ www.astrohn.ru, www.astrohn.com, Лыткарино, Моск.обл., Россия \\ 2 Санкт-Петербургский университет точной механики и оптики (Университет ИТМО), \\ www.ifmo.ru, Санкт-Петербург, Россия
}

\begin{abstract}
Разработана двухступенчатая микрокриогенная система Стирлинга для криостатирования модуля фотоприемного устройства с редкоземельным комбинированным регенератором в первой ступени охлаждения и магнитокалорическим охлаждением во второй ступени. Описана конструкция системы, которая обеспечивает расширенный интервал температур криостатирования при повышенном КПД вблизи температуры 80К.
\end{abstract}

Ключевые слова: микрокриогенная система Стирлинга, криостатирование ФПУ, лантаноиды

\section{Micro-Cryogenic Stirling Cooler with a Combined Regenerator and Magnetocaloric Cooling Step}
A.V.Samvelov', S. G. Yasev' ${ }^{1}$, A.S. Moskalenko', V.V.Startsev' , O. V. Pakhomov²
1 JSC "Opto-mechanical design office "ASTRON", www.astrohn.ru, www.astrohn.com, Lytkarino, Moscow.region, Russia
2 St. Petersburg University of precision mechanics and optics (ITMO University), www.ifmo.ru, St. Petersburg, Russia

\begin{abstract}
The article describes the developed two-stage microcryogenic Stirling system for cryostatting the photodetector module. The design has a rare-earth combined regenerator in the first stage of cooling and magnetocaloric cooling in the second stage. The design provides an extended range of cryostatting temperatures and an increased efficiency near a temperature of $80 \mathrm{~K}$.
\end{abstract}

Key words: Stirling micro-cryogenic system, cryostat for the photodetector, the lanthanides

\section{ВВЕДЕНИЕ}

Специалисты АО «ОКБ "АСТРОН» разработали двухступенчатую микрокриогенную систему (МKC) Стирлинга для криостатирования модуля фотоприемного устройства (МФПУ) с редкоземельным комбинированным регенератором в первой ступени охлаждения и магнитокалорическим (MK) охлаж- дением во второй ступени. Детандер МКС имеет встроенный активный регенератор. Вторая ступень охлаждения представляет собой редкоземельную насадку регенератора и неподвижного постоянного кольцевого магнита для поддержания магнитокалорического охлаждения. Микрокриогенная система предназначена для охлаждения модуля 
фотоприемного устройства и обеспечивает расширенный интервал температур криостатирования при повышенном КПД вблизи температуры 80K.

Низкотемпературная ступень созданной МКС работает на основе МК-эффекта. В ее состав входит комбинированный регенератор с областью насадки в "холодной" зоне, выполненной из редкоземельного металла - гольмия, “теплая" зона насадки регенератора заполнена элементами, изготовленными из стали марки 12Х18Н10Т в виде набранных в пакет сетчатых дисков.

\section{ПОСТАНОВКА ЗАДАЧИ}

Редкоземельные металлы (лантаноиды), обладающие особыми физическими свойствами, могут быть использованы в современном промышленном производстве для создания преобразователей энергии. Одной из таких технологий является магнитное охлаждение, в основе которого лежит МК-эффект. В последние десятилетия наблюдается рост интереса к исследованию МК-эффекта для его использования в микрокриогенной технике [1-4]. В этот период было разработано и запатентовано множество рефрижераторов, охладителей и тепловых насосов с использованием и основной, и в дополнительной ступенях охлаждения на основе MK-эффекта, реализуемого при помощи лантаноидов. Это явление наблюдается при адиабатном размагничивании парамагнитного материала, обладающего хорошими магнитными свойствами при температурах вблизи температуры Кюри (Нееля). В частности, материал обладает высоким МК-эффектом: в изотермических условиях рабочий элемент из такого материала намагничивается в магнитном поле, нагреваясь при этом, а затем, при съеме магнитного поля, размагничивается. В процессе размагничивания элемент, охлаждаясь, обеспечивает криостатирование объекта.

\section{ОСОБЕННОСТИ КОНСТРУКЦИИ}

Разработанная в АО "ОКБ "АСТРОН" МКС Стирлинга имеет в первой ступени охлаждения активный магнитный регенератор на основе гольмия, во второй ступени охлаждения МК-охладитель и неподвижные постоянные магниты. Система обладает пониженным энергопо- треблением и расширенным интервалом рабочих температур при повышенном КПД вблизи температуры криостатирования 80K. В отличие от известных МКС Стирлинга, появляется дополнительная ступень охлаждения криоагента, работающая на МК-эффекте, приводящая к росту КПД и расширению рабочего диапазона температур [5-7].

\section{ЦЕЛЬ ИССЛЕДОВАНИЙ}

Цель исследований состояла в том, чтобы изучить возможности работы $\mathrm{MKC,} \mathrm{в} \mathrm{конструкции} \mathrm{которой}$ лантаноидная часть магнитокалорического охладителя одновременно является "холодным" участком насадки комбинированного регенератора, что повышает эффективность регенерации. Эскиз конструкции МКС-охладителя иллюстрирует рисунок.

\section{ТЕОРЕТИЧЕСКИЕ ОСНОВЫ}

Изотермическое расширение в новом конструктивном исполнении цикла Стирлинга выполняется детандерным поршнем (10) при движении вправо (см. рисунок). Газообразный гелий, являющийся рабочим газом цикла, при этом расширяется и, отдавая работу, охлаждается, отбирая тепло от охлаждаемого объекта (6).

Холодопроизводительность в идеальном цикле оценивается уравнением:

$$
\mathrm{Q}_{0}=M R T_{0} \ln \left(V_{1} / V_{2}\right),
$$

где $M$ - массовый расход гелия, измеряемый в кг/с; $\mathrm{R}$ - газовая постоянная гелия, Дж/(кг·K), $\mathrm{T}_{\mathrm{o}}$ - температура криостатирования, измеряемая в градусах $\mathrm{K}$; $\mathrm{V}_{1}$, 
$V_{2}$ - максимальный и минимальный объемы цикла соответственно, измеряемые в кубических метрах.

Изохорное охлаждение осуществляется в регенераторе, в котором есть две области (насадки): основную, выполненную из стали 12Х18Н10T (5), и парамагнитную (лантаноидную), выполненную из мелкозернистого поликристаллического гольмия (9). Сконструированный таким образом комбинированный регенератор с 20-и процентным заполнением по длине гольмием со стороны зоны криостатирования обладает высокой теплопроводностью в диапазоне температур 60-80K. Такое конструктивное решение позволит более эффективно осуществлять регенерацию рабочего газа (гелия). Эффективность регенерации определяется потерями от недорекуперации регенератора:

$$
\Delta \mathrm{T}_{\mathrm{H}}=\frac{M_{2} \cdot c_{p 2} \cdot\left(\mathrm{T}_{2}-\mathrm{T}_{x}\right)}{M_{\mathrm{H}} \cdot c_{H}},
$$

где $M_{2}, M_{H}$ - масса гелия и насадки регенератора соответственно, кг; $c_{p 2}, c_{H}$ - теплоемкость гелия и насадки регенератора соответственно Дж/(кг·K), $\mathrm{T}_{2}, \mathrm{~T}_{x}-$ соот $^{-}$ ветственно температура "горячего" и "холодного" дутья, $\mathrm{K}$.

Усредненная удельная теплоемкость стали 12XН10T, применяемой в предыдущих разработках [патент на полезную модель № 142459], в интервале температур 60-80K составляет около 150 Дж/(кг K). В то же время у чистого гольмия в данном диапазоне температур удельная теплоемкость составляет около 220 Дж/(кг·K). Следовательно, потери от недорекуперации при замене в зоне криостатирования участка насадки регенератора из 12X18H10T (5) на участок из гольмия (9) должны снизиться на 25-30\% при прочих равных условиях. КПД микрокриогенной системы возрастет на $10-15 \%$.

Вторая ступень охлаждения в микрокриогенной системе Стирлинга, магнитокалорическая, включает в себя парамагнитную гольмиевую часть регенеративного теплообменника (9) и кольцевой активный магнитный элемент (8).

Работа второй ступени криостатирования реализуется следующим образом. Детандерный поршень (10), находясь в крайнем левом положении, перед реализацией первой фазы криостатирования расположен концентрически в кольцевом активном магнитном элементе (8). При этом парамагнитная часть регенеративного теплообменника находится под воздействием магнитного поля напряженностью 2 Тл.Происходит изотермическое намагничивание гольмия. Теплота намагничивания снимается при работе устройства. Затем в процессе расширения, перемещения детандерного поршня вправо и последующего охлаждения гелия гольмиевая часть регенератора (9) выходит из поля действия магнита (8). Выполняется процесс адиабатного размагничивания с понижением температуры гольмия, описывающийся выражением для холодопроизводительности при магнитокалорическом эффекте [8]:

$$
\Delta Q_{M K}=-T\left(\frac{\partial M}{\partial T}\right)_{P, H} \Delta H,
$$

где $M$ - намагниченность гольмия, А/м; Т - температура, $\mathrm{K} ; \mathrm{H}$ - напряженность магнитного поля, Тл.

Обе ступени криостатирования работают синхронно во времени. При выходе микрокриогенной системы на режим частота перемещений детандерного поршня (10) снижается, что дает возможность эффективной реализации МК-эффекта, поскольку при повышенных частотах из-за наличия магнитного гистерезиса активного магнита (8) МК-эффекта можно не получить. Вторая ступень криостатирования позволит понизить температуру криостатирования до 60-65 K.

В качестве материала активного магнита используется интерметаллический редкоземельный материал - неодим-железо-бор. "Холодная" область регенератора изготавливается из парамагнитного поликристаллического гольмия высокой чистоты мелкозернистой структуры. Основная область насадки регенератора выполнена в виде сетчатых элементов из нержавеющей стали марки 12X18H10Т [9-11].

Предлагаемое устройство охлаждения Стирлинга с магнитокалорической ступенью криостатирования позволит расширить диапазон температур криостатирования до 80-60К, повысить КПД микрокриогенной системы на 10-15\%, снизить потребляемую мощность на $15 \%$.

\section{РЕЗУЛЬТАТЫ ИССЛЕДОВАНИЙ}

Исследования показали, что созданная конструкция обеспечивает исполнение технического решения. В активном регенераторе достигается эффективная регенерация тепла и во второй магнитокалорической ступени микрокриогенной системы создается дополнительное охлаждение.

Таким образом, конструктивное решение обеспечивает снижение температуры криостатирования до 60K, при этом потребление мощности снижается на 12-15\% по сравнению с известными техническими решениями, а КПД устройства повышается на 8-10\%. 


\section{ЗАКЛЮЧЕНИЕ}

Разработана двухступенчатая микрокриогенная система для криостатирования модуля фотоприемного устройства на основе газовой криогенной машины Стирлинга со ступенью окончательного охлаждения на основе магнитокалорического эффекта. Рабочее тело первой ступени - газообразный гелий, рабочее тело второй ступени - двухфункциональный эффективный активный регенеративный теплообменник для предварительного охлаждения, выполненный в "холодной" зоне из редкоземельного металла - гольмия. В первой ступени реализуется процесс изотермического расширения гелия с подводом тепла по традиционному циклу Стирлинга, во второй ступени охлажденный гелий окончательно охлаждается в процессе снятия магнитного поля с магнитокалорической ступени (редкоземельной части регенеративного теплообменника) - реализуется магнитокалорический эффект. Таким образом, после окончательного охлаждения гелий способен довести температуру криостатирования объекта до температуры вблизи 60K, сохраняя при этом достаточную энергетическую эффективность цикла.

На конструкцию МКС подана заявка на изобретение в Федеральный институт промышленной собственности ФИПС.

\section{СПИСОК ЛИТЕРАТУРЫ}

1. Андреенко А.С., Белов К.П., Никитин С.А., Тишин А.М. Магнитокалорические эффекты в редкоземельных магнетиках. Успехи физических наук. 1989; 158(4): 597.

2. Тарасов В.В., Якушенков Ю.Г. Инфракрасные системы "смотрящего» типа. - М.: "ЛОГОС". 2004.

3. Формозов Б. Н. Аэрокосмические фотоприемные устройства в видимом и инфракрасном диапазонах. - С-Пб: СПбГУАП. 2002

4. Политова Г.А., Бурханов Г.С, Терешина И. С., Каминска Т. П., Чжан В. Б., Терешина Е.А. Влияние легирования алюминием и железом на структуру, магнитные и магнитокалорические свойства многокомпонентных сплавов Tb-Dy-Ho-Co. Журнап технической физики. 2017; 87(4):4-5.

5. Самвелов А.В., Ясев С. Г., Москаленко А.С., Старцев В. В., Пахомов О. В. Интегральные микрокриогенные систем Стирлинга в составе криостатируемых фотоприемных модулей на основе матриц длинноволновой ИК-области. Фотоника. 2019;13(1):58-64.

6. Еремчук А.И., Самвелов А. В. и др. Оптимизация давления рабочего газа при промывке перед заполнением микрокриогенных систем охлаждения МФпУ. Успехи прикладной физики. 2013; 1(2): 224-226.

7. Аракелов Г.А., Самвелов А. В. Вопросы оптимизации режимов электропитания термоэлектрических охладителей фотоприемников в составе оптико-электронной аппаратуры. Прикпадная физика. 2012; 6: 78-84.

8. Суслов А.Д. Криогенные газовые машины. - М.: Машиностроение. 1982

9. Нефедьев С. П., Дема Р. Р., Молочкова О.С. Материаповедение. - Магнитогорск: Магнитогорский государственный технический университет. им. Г. И. Носова. 2014.

10. Колесников А. М., Самвелов А. В., Словеснов К. В. Микрокриогенные системы Стирлинга в интегральном исполнении с повышенным ресурсом работы. Прикиадная физика. 2010;2: 80-82.

11. Трошкин Ю.С., Чапкевич А. Л., Горбунов Е. К., Посевин О. П., Самвелов А. В. Прикиадная физика.1999 (3):60-65.

\section{REFERENCE}

1. Andreenko A.S., Belov K.P., Nikitin S.A., Tishin A.M. Magnitokaloricheskie effekty V redkozemel'nyh magnetikah. Uspekhi frzicheskih nauk. 1989; 158(4): 597.

2. Tarasov V.V., Yakushenkov Yu. G. Infrakrasnye sistemy usmotryashchegou tipa. - M.: "Logos". 2004.

3. Formozov B.N. Aerokosmicheskie fotopriemnye ustrojstva v vidimom i infrakrasnom diapazonah. S-Pb: SPbGUAP. 2002

4. Politova G.A., Burhanov G.S, Tereshina I.S., Kaminska T.P., Chzhan V.B., Tereshina E.A. Vliyanie legirovaniya alyuminiem i zhelezom na strukturu, magnitnye i magnitokaloricheskie svojstva mnogokomponentnyh splavov Tb-Dy-Ho-Co. Zhurnal tekhnicheskoj fiziki. 2017; 87(4):4-5.

5. Samvelov A.V., Yasev S. G., Moskalenko A.S., Starcev V.V., Pahomov O.V. Integral'nye mikrokriogennye sistem Stirlinga v sostave kriostatiruemyh fotopriemnyh modulej na osnove matric dlinnovolnovoj IK-oblasti. Photonics Russia. 2019;13(1):58-64.

6. Eremchuk A.I., Samvelov A.V. i dr. Optimizaciva davleniya rabochego gaza pri promyvke pered zapolneniem mikrokriogennyh sistem ohlazhdeniya MFPU. Uspekhi prikladnoj friki. 2013; 1(2): 224-226.

7. Arakelov G.A., Samvelov A.V.Voprosy optimizacii rezhimov elektropitaniya termoelektricheskih ohladitelej fotopriemnikov v sostave optiko-elektronnoj apparatury. Prikladnava fizika. 2012; 6: 78-84.

8. Suslov A.D. Kriogennye gazovye mashiny. - M.: Mashinostroenie. 1982.

9. Nefed'ev S.P., Dema R. R., Molochkova O.S. Materialovedenie. - Magnitogorsk: Magnitogorsk state technical University named G. I. Nosov. 2014.

10. Kolesnikov A.M ., Samvelov A.V., Slovesnov K.V. Mikrokriogennye sistemy Stirlingav integral'nom ispolnenii s powsshennym resursom raboty. Prikladnava fizika. 2010;2: 80-82.

11. Troshkin Yu.S., Chapkevich A. L., Gorbunov E. K., Posevin O.P., Samvelov A.V. Prikladnaya fizika.1999; (3): 60-65.

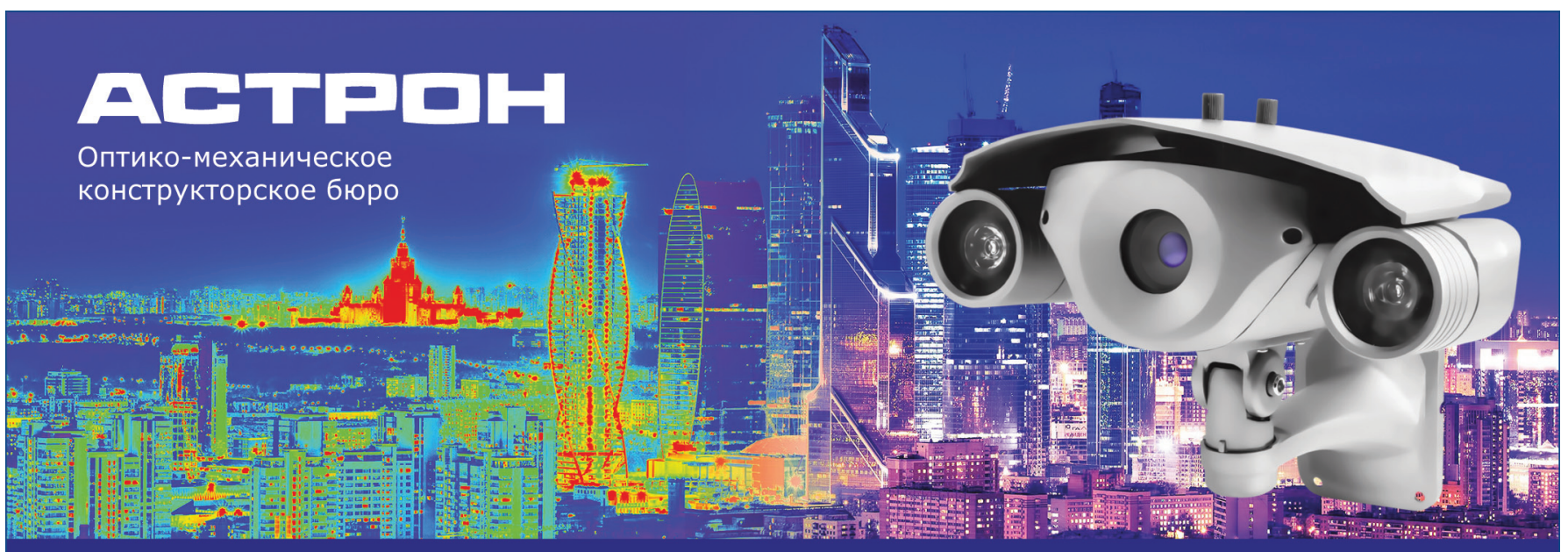

ПРОИЗВОДСТВО ТЕПЛОВИЗИОННЫХ СИСТЕМ БЕЗОПАСНОСТИ 140080, МО, г. Лыткарино, ул. Парковая, д.1; тел: +7 (495) 215-13-82; info@astrohn.ru, www.astrohn.ru 